\title{
ICE review
}

\author{
A review of recent developments at the Institution of Civil Engineers by ICE president John Armitt. \\ For further information please contact the communications office on +44 207665 2107, email \\ communications@ice.org.uk or visit www.ice.org.uk//news-public-affairs.
}

\section{Assessing UK infrastructure needs}

As announced in my presidential address (page 6), ICE is leading a coalition of business, academic, environment and industry experts to produce a 'national needs assessment' for UK infrastructure. Due for publication in autumn 2016, it will set out what the UK is likely to need from its infrastructure up to the year 2050.

The coalition will draw from data, analysis, open consultations and evidence hearings. We will consider factors such as climate change and population growth, and we will then set out different options for meeting those needs. The document will be designed to inform both national and regional infrastructure plans.

The work will also feed into the newly formed UK National Infrastructure Commission.

I am delighted to be one of the commissioners and will be responsible for examining and gathering evidence on the UK's long-term infrastructure needs. ICE's assessment will form a vital part of this evidence base and has been welcomed by the commission's chair Andrew Adonis.

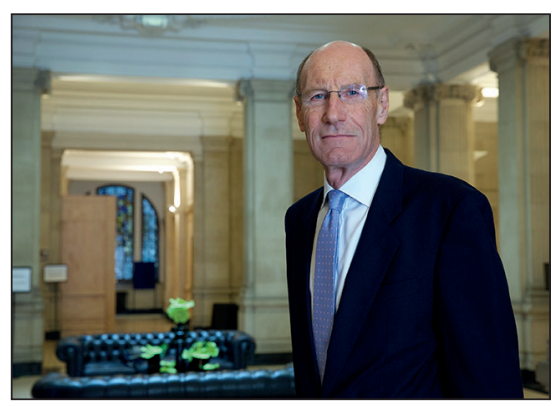

ICE president John Armitt is chairing an industry coalition to assess the UK's infrastructure needs

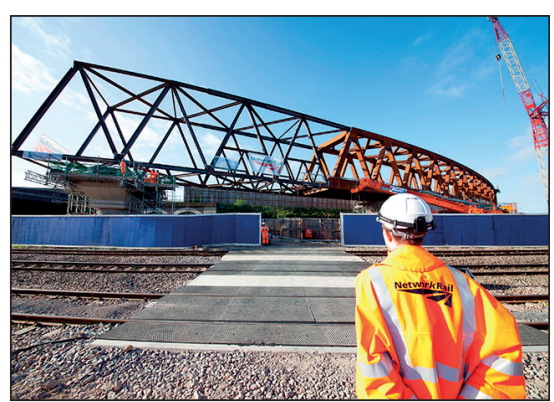

A total of $85 \%$ of the British public want to see improvements to national infrastructure

\section{Understanding public attitudes}

I was pleased to speak in December at the launch of an independent survey on public attitudes to infrastructure, hosted by ICE. It found $87 \%$ of the British public support infrastructure investment and $85 \%$ want to see improvements. People also want to be kept informed about infrastructure and involved in decisions

Without sufficient political and public support, important projects simply cannot proceed. It is vital for civil engineers to explain - in plain language - what they are trying to achieve and why, to be prepared to consider alternative solutions and to see things from the public's perspective.

I argued in my address that the profession has become lost in the 'what' and 'how' when it comes to infrastructure, and does not spend long enough considering the 'why'. Bringing about such a change in our approach, and achieving a positive shift in the public's attitudes, will not happen overnight. The challenge for us all ICE, government and the new National Infrastructure Commission - is to open up the debate and address the public's fears and concerns.
Producing new ethics and BIM tools

ICE has launched an ethics web tool and 'app' to help civil engineers navigate difficult ethical problems in the workplace. We have also launched a building information modelling (BIM) 'maturity measurement tool' to help members prepare for the UK government's April deadline for BIM level 2.

The 'Say No' ethics web tool and app (http://ice.saynotoolkit.net/), developed with the Institute of Business Ethics, provides 'in the moment' practical guidance on how to handle a range of situations. These include potential conflicts of interest, anti-competitive situations, offers of gifts and requests to authorise unplanned payments.

The new Excel-based BIM tool (https://www.ice.org.uk/disciplines-andresources/best-practice), developed jointly by the ICE BIM action group and Atkins, is designed to promote a common view of BIM best practice. It demystifies BIM, drives awareness of what BIM best practice looks like and helps to raise BIM capability across design and engineering disciplines. It builds on a concept originally developed by Arup as part of the CIC Research Group's BIM project execution guide.

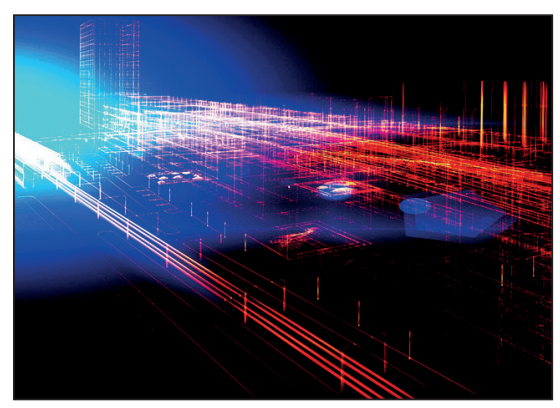

ICE's new BIM maturity tool will help members prepare for the UK government's April 2016 deadline for BIM level 2 